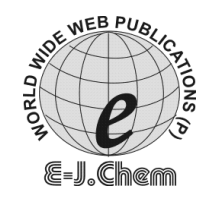

http://www.e-journals.net

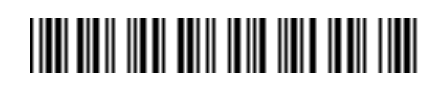

ISSN: 0973-4945; CODEN ECJHAO

E-Journal of Chemistry

Vol. 4, No. 3, pp. 408-414, July 2007

\title{
Effect of Schiff's Bases as Corrosion Inhibitors on Mild Steel in Sulphuric Acid
}

\author{
R. K. UPADHYAY*, S. P. MATHUR \\ Department of Pure and Applied Chemistry, \\ MDS University, Ajmer, India. \\ *Department of Chemistry, \\ Government College, Ajmer, India \\ alwayz_rajesh@yahoo.co.in
}

Received 11 January 2007; Accepted 23 February 2007

\begin{abstract}
Mass loss and thermometric methods have been used to study the corrosion inhibitory effect of synthesised Schiff's bases viz. $N$-(furfurilidine) - 4- methoxy aniline $\left(\mathrm{SB}_{1}\right), N$-(furfurilidine) - 4- methylaniline $\left(\mathrm{SB}_{2}\right), N$ (salicylidine) - 4- methoxy aniline $\left(\mathrm{SB}_{3}\right), N$-(cinnamalidine) - 4 -methoxy aniline $\left(\mathrm{SB}_{4}\right)$ and $N$-(cinnamalidine) - 2-methylaniline $\left(\mathrm{SB}_{5}\right)$ on mild steel in sulphuric acid solutions. Results show that both methods have good agreement with each other and inhibition efficiency depends upon the concentration of inhibitor as well as that of acid. Maximum inhibition efficiency is shown at highest concentration of Schiff's bases at the highest strength of acid.
\end{abstract}

Keywords: Schiff's bases, Corrosion, Inhibition efficiency, Corrosion rate, Surface Coverage.

\section{Introduction}

Mild steel is an important metal regarding to its wide applications in industry in various mechanical and structural purposes. It is widely used in engineering fabrications like bridge work, buildings, steam engine parts and automobiles etc. It is much prone to corrosion while in use by different corrosion agents of which acids like $\mathrm{HCl}$ and $\mathrm{H}_{2} \mathrm{SO}_{4}$ are most common and dangerous. $\mathrm{HCl}$ and $\mathrm{H}_{2} \mathrm{SO}_{4}$ have been used for drilling operations, picking baths and in decaling processes ${ }^{1}$.

Corrosion of mild steel and its alloys in different acid media has been extensively studied $^{2-5}$. Corrosion rate of mild steel is affected by $\mathrm{pH}$ of solution, metal dissolved oxygen and temperature. It is adversely affected in the $\mathrm{pH}$ range 4 to 10 but fairly resistant to attack 
by alkali. The effect of certain organic compounds bearing hetero atoms have been studied $^{6-12}$ as corrosion inhibitors for mild steel. Many investigators ${ }^{13-15}$ have studied the effect of some nitrogen containing compounds on corrosion of mild steel in different acid media. Extracts of some naturally occurring Plants containing some alkaloids have also been found effective corrosion inhibitors ${ }^{16-17}$ in sulphuric acid for mild steel.

Generally the heterogenous organic compounds having higher basicity and electron density on the hetero atoms like $\mathrm{O}, \mathrm{N}, \mathrm{S}$ have tendency to resist corrosion. Nitrogen and sulphur are the active centers for the process of adsorption on the metal surface.

In the present investigation the inhibition efficiency of five synthesised Schiff's bases viz. $N$-(furfurilidine) - 4- methoxy aniline $\left(\mathrm{SB}_{1}\right), N$-(furfurilidine) - 4- methylaniline $\left(\mathrm{SB}_{2}\right)$, $N$-(salicylidine) - 4- methoxy aniline $\left(\mathrm{SB}_{3}\right), N$-(cinnamalidine) - 4 -methoxy aniline $\left(\mathrm{SB}_{4}\right)$ and $N$-(cinnamalidine) - 2-methylaniline $\left(\mathrm{SB}_{5}\right)$ have been investigated for mild steel in sulphuric acid.

\section{Experimental}

Rectangular specimens of mild steel of approximate composition $99.3 \% \mathrm{Fe}, 0.12 \% \mathrm{C}, 0.4 \%$ $\mathrm{Mg}, 0.14 \% \mathrm{Si}$ and $0.04 \% \mathrm{~S}$ of dimension $2.5 \mathrm{~cm} \times 2.0 \mathrm{~cm} \times 0.05 \mathrm{~cm}$ containing a small hole of about $2 \mathrm{~mm}$ diameter near the upper edge were taken. Specimens were cut from the centre of a steel sheet and were thoroughly cleaned, buffed, rubbed with emery paper to obtain mirror like spotless surface. The specimens were finally degreased by using acetone. All chemicals used for the synthesis of Schiff's bases were of analytical reagent grade and solutions of sulphuric acid were prepared in double distilled water.

Each specimen was suspended by a V-shaped glass hook made by fine capillary glass tubes and immersed in a glass beaker containing $50 \mathrm{~mL}$ of test solutions at room temperature. After the exposure of sufficient time the test specimen was taken out, cleaned under running water and finally dried with hot air dryer. The percentage corrosion inhibition efficiency was calculated as ${ }^{18}$

$$
\eta \%=\frac{\left(\Delta M_{u}-\Delta M_{i}\right)}{\Delta M_{u}} \times 100
$$

where, $\quad \Delta \mathrm{M}_{\mathrm{u}}=$ Mass loss of metal in uninhibited solution.

$\Delta \mathrm{M}_{i}=$ Mass loss of metal in inhibited solution.

The degree of surface coverage of metal $(\theta)$ was calculated as:

$$
\theta=\frac{\left(\Delta M_{u}-\Delta M_{i}\right)}{\Delta M_{i}}
$$

The corrosion rate in mmpy (milli mils penetration per year) can be obtained by following equation ${ }^{20}$.

$$
\text { Corrosion rate (mmpy) }=\frac{87.6 \Delta M}{A T d}
$$

Where $\quad \Delta \mathrm{M}=$ Mass loss in $\mathrm{mg}$.

$A=$ Exposed area of metal surface in $\mathrm{cm}^{2}$.

$T=$ Time of exposure in hours

$d=$ metal density in $\mathrm{gm} \mathrm{cm}^{-3}$

and $1 \mathrm{mil}=0.001$ inch.

Corrosion inhibition efficiencies were also calculated by other method i.e. thermometric method in which the variation of temperature of the system is followed as a 
function of time. The method was first introduced by Mylius ${ }^{21}$. The method involves the immersion of single specimen of dimensions $2.5 \mathrm{~cm} \times 2.0 \mathrm{~cm} \times 0.05 \mathrm{~cm}$ in an insulating reactions chamber having $50 \mathrm{~mL}$ of solution at an initial room temperature. Temperature changes were measured at regular intervals using a thermometer with a precision of $0.01^{\circ} \mathrm{C}$. The increase in temperature was slow initially and rapid afterwards, reaching a maximum value and then started to decrease. The maximum temperature was noted. Percentage corrosion inhibition efficiencies were calculated as

$$
\eta \%=\left(\frac{R N_{f}-R N_{i}}{R N_{f}}\right) \times 100
$$

where $R N_{f}=$ Reaction number in free solution.

$R N_{i}=$ Reaction number in inhibited solution.

Reaction number $R N\left(K \mathrm{~min}^{-1}\right)$ is defined as :

$$
R N=\frac{\left(T_{m}-T_{i}\right)}{t}
$$

where $\quad T_{m}=$ Maximum temperature attained by solution.

$T_{i}=$ Initial temperature of solution.

$t=$ Time required to attain maximum temperature.

\section{Results and Discussion}

Mass loss and corresponding corrosion inhibition efficiency in different strengths of $\mathrm{H}_{2} \mathrm{SO}_{4}$ in different concentrations of inhibitors are depicted in Table 1. It is observed from the Table that percentage inhibition efficiency increases with the increase in the concentration of inhibitor. It is also clear from the Table 1 that each inhibitor has higher efficiency at higher concentration of acid and maximum efficiency is shown at the highest concentration of acid (2N). The maximum efficiency $(97.01 \%)$ was shown by $\mathrm{N}$ (salicylidine)-4-methoxy aniline $\left(\mathrm{SB}_{3}\right)$.

Inhibition efficiencies were also determined by another method i.e. thermometric method. Since no significant changes in temperature were observed for lower concentrations of $\mathrm{H}_{2} \mathrm{SO}_{4}$, so observations were taken for higher $(1 \mathrm{~N}, 2 \mathrm{~N}$ and $3 \mathrm{~N})$ concentrations of acid. The results are depicted in Table 2.

The results shown by thermometric methods have same trends as observed in mass loss method. Thus, both methods have good agreement with each other. In this method also the maximum efficiency was shown by $N$-(salicylidine) -4 - methoxy aniline $\left(\mathrm{SB}_{3}\right)$ at the highest concontration $(3 \mathrm{~N})$ of $\mathrm{H}_{2} \mathrm{SO}_{4}$. The variation of reaction number (RN) with inhibitor concentration is depicted graphically for $1.0 \mathrm{~N} \mathrm{H}_{2} \mathrm{SO}_{4}$ in Figure 1. The plots show linear behaviour with negative slope, it means reaction number decreases with increasing inhibitor concentration.

Organic molecules having hetero atoms like $\mathrm{N}, \mathrm{O}$ and $\mathrm{S}$ adsorb on the metallic surface. In the present case Schiff's bases adsorb on the surface of mild steel, thus reduce the exposed surface area for electrochemical reaction. The surface coverage $(\theta)$ with increasing concentrations of Schiff's bases are depicted in Table 3. Nitrogen atom present in Schiff's base acts as the reactive centre because of high electron density which results in a monolayer of Schiff's base on the metallic surface. 
Table 1. Mass loss $\Delta \mathrm{M}$ and inhibition efficiency $\eta$ for Mild Steel in $\mathrm{H}_{2} \mathrm{SO}_{4}$ solutions with given inhibitor additions

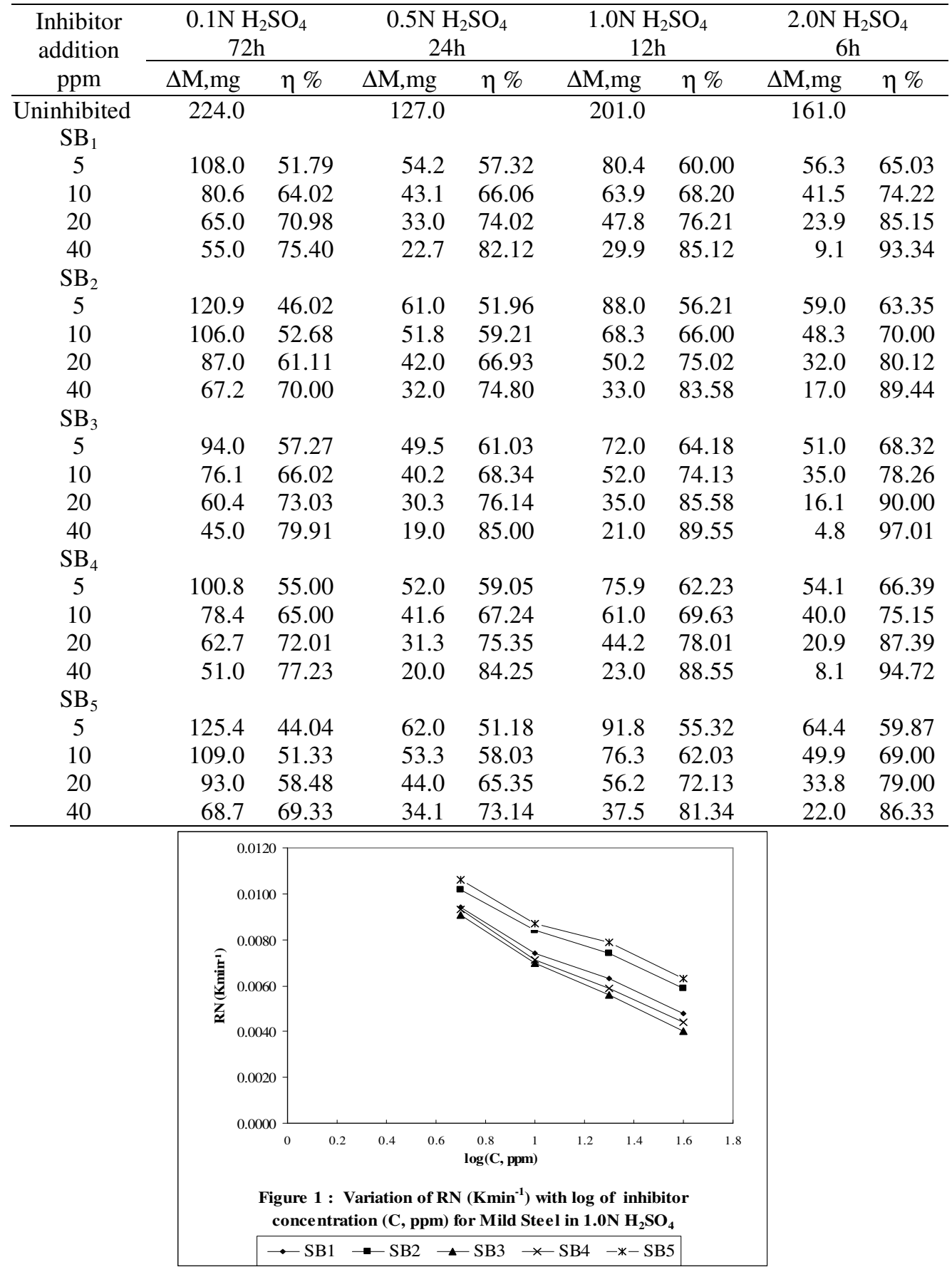


Table 2. Reaction Number (RN) and inhibition efficiency for Mild Steel in $\mathrm{H}_{2} \mathrm{SO}_{4}$ solution with given inhibitor additions at $25 \pm 0.01^{\circ} \mathrm{C}$.

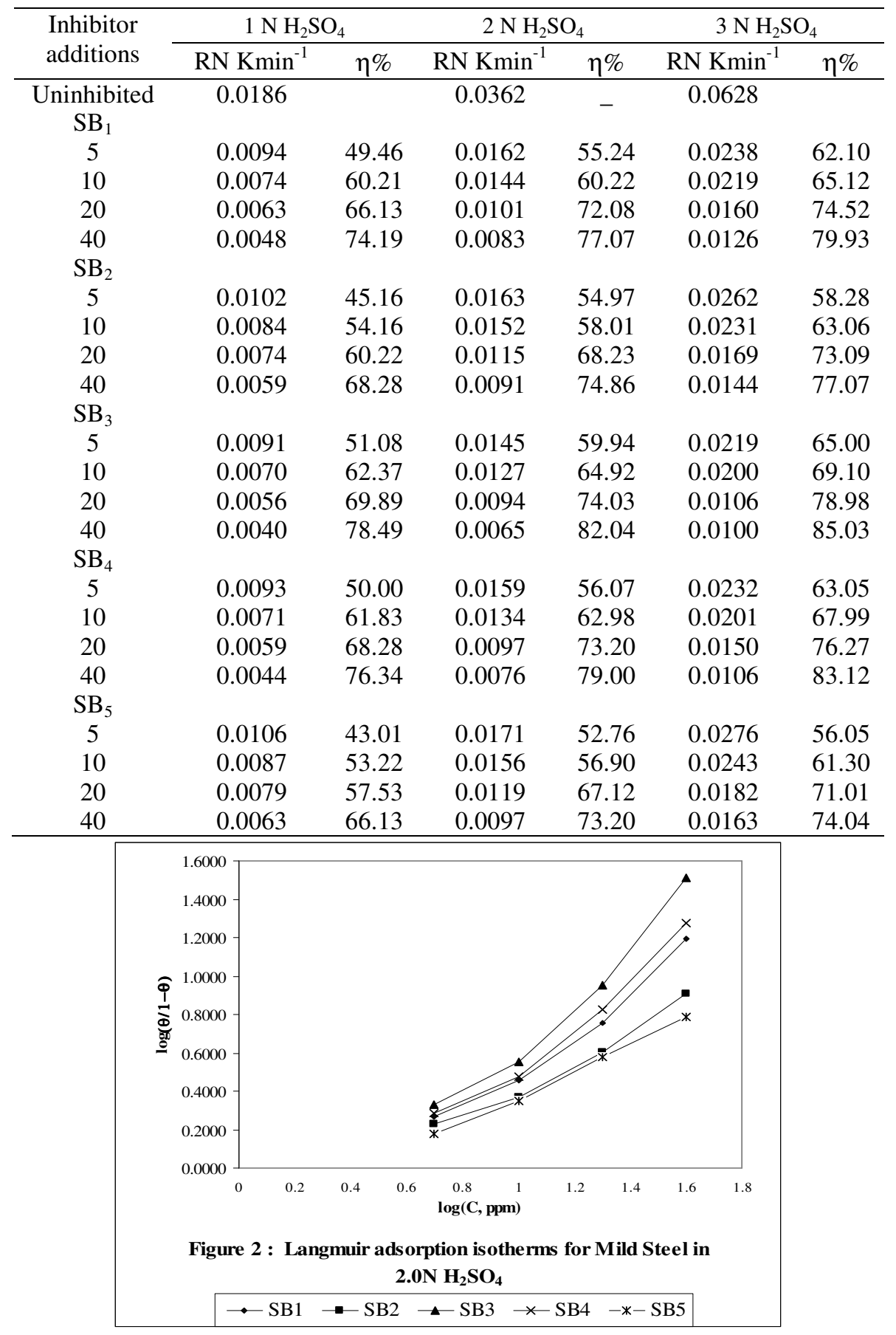


Table 3. Suface coverage $(\theta)$ for Mild Steel in $\mathrm{H}_{2} \mathrm{SO}_{4}$ solutions with given inhibitor additions. Effective area of specimen $=5.0 \mathrm{~cm}^{2}$

\begin{tabular}{|c|c|c|c|c|c|c|c|c|}
\hline \multirow[b]{2}{*}{$\begin{array}{c}\text { Inhibitor } \\
\text { addition } \\
\text { ppm }\end{array}$} & \multicolumn{2}{|c|}{$0.1 \mathrm{~N} \mathrm{H}_{2} \mathrm{SO}_{4}, 72 \mathrm{~h}$} & \multicolumn{2}{|c|}{$0.5 \mathrm{~N} \mathrm{H}_{2} \mathrm{SO}_{4,} 48 \mathrm{~h}$} & \multicolumn{2}{|c|}{$1.0 \mathrm{~N} \mathrm{H}_{2} \mathrm{SO}_{4}, 12 \mathrm{~h}$} & \multicolumn{2}{|c|}{$2.0 \mathrm{~N} \mathrm{H}_{2} \mathrm{SO}_{4}, 6 \mathrm{~h}$} \\
\hline & $\begin{array}{c}\text { Surface } \\
\text { Coverage } \\
(\theta)\end{array}$ & $\log \left(\frac{\theta}{1-\theta}\right)$ & $\begin{array}{c}\text { Surface } \\
\text { Coverage } \\
(\theta)\end{array}$ & $\log \left(\frac{\theta}{1-\theta}\right)$ & $\begin{array}{c}\text { Surface } \\
\text { Coverage } \\
(\theta)\end{array}$ & $\log \left(\frac{\theta}{1-\theta}\right)$ & $\begin{array}{c}\text { Surface } \\
\text { Coverage } \\
(\theta)\end{array}$ & $\log \left(\frac{\theta}{1-\theta}\right)$ \\
\hline \multicolumn{9}{|l|}{$\mathrm{SB}_{1}$} \\
\hline 5 & 0.52 & 0.0348 & 0.57 & 0.1224 & 0.60 & 0.1761 & 0.65 & 0.2688 \\
\hline 10 & 0.64 & 0.2499 & 0.66 & 0.2881 & 0.68 & 0.3274 & 0.74 & 0.4542 \\
\hline 20 & 0.71 & 0.3889 & 0.74 & 0.4543 & 0.76 & 0.5006 & 0.85 & 0.7533 \\
\hline 40 & 0.75 & 0.4771 & 0.82 & 0.6585 & 0.85 & 0.7533 & 0.94 & 1.1950 \\
\hline \multicolumn{9}{|l|}{$\mathrm{SB}_{2}$} \\
\hline 5 & 0.46 & -0.0696 & 0.52 & 0.0348 & 0.56 & 0.1047 & 0.63 & 0.2311 \\
\hline 10 & 0.53 & 0.0522 & 0.59 & 0.1581 & 0.66 & 0.2881 & 0.70 & 0.3679 \\
\hline 20 & 0.61 & 0.1943 & 0.67 & 0.3076 & 0.75 & 0.4771 & 0.80 & 0.6021 \\
\hline 40 & 0.70 & 0.3680 & 0.75 & 0.4771 & 0.84 & 0.7202 & 0.89 & 0.9080 \\
\hline \multicolumn{9}{|l|}{$\mathrm{SB}_{3}$} \\
\hline 5 & 0.57 & 0.1224 & 0.61 & 0.1943 & 0.64 & 0.2499 & 0.68 & 0.3274 \\
\hline 10 & 0.66 & 0.2881 & 0.68 & 0.3274 & 0.74 & 0.4543 & 0.78 & 0.5497 \\
\hline 20 & 0.73 & 0.4319 & 0.76 & 0.5006 & 0.83 & 0.6886 & 0.90 & 0.9542 \\
\hline 40 & 0.80 & 0.6021 & 0.85 & 0.7533 & 0.90 & 0.9542 & 0.97 & 1.5096 \\
\hline \multicolumn{9}{|l|}{$\mathrm{SB}_{4}$} \\
\hline 5 & 0.55 & 0.0872 & 0.59 & 0.1581 & 0.62 & 0.2126 & 0.66 & 0.2881 \\
\hline 10 & 0.65 & 0.2688 & 0.67 & 0.3076 & 0.70 & 0.3680 & 0.75 & 0.4771 \\
\hline 20 & 0.72 & 0.4102 & 0.75 & 0.4771 & 0.78 & 0.5497 & 0.87 & 0.8256 \\
\hline 40 & 0.77 & 0.5248 & 0.84 & 0.7201 & 0.89 & 0.9080 & 0.95 & 1.2788 \\
\hline \multicolumn{9}{|l|}{$\mathrm{SB}_{5}$} \\
\hline 5 & 0.44 & -0.1047 & 0.51 & 0.0174 & 0.54 & 0.0696 & 0.60 & 0.1761 \\
\hline 10 & 0.51 & 0.0174 & 0.58 & 0.1402 & 0.62 & 0.2126 & 0.69 & 0.3475 \\
\hline 20 & 0.58 & 0.1402 & 0.65 & 0.2688 & 0.72 & 0.4102 & 0.79 & 0.5754 \\
\hline 40 & 0.69 & 0.3475 & 0.73 & 0.4319 & 0.81 & 0.6297 & 0.86 & 0.7883 \\
\hline
\end{tabular}

The presence of electron releasing group $-\mathrm{OCH}_{3}$ on $\mathrm{SB}_{3}$ increases the electron density, thus increases the inhibition efficiency. The higher efficiency in higher concentration of $\mathrm{H}_{2} \mathrm{SO}_{4}$ is may be due to the fact that under strong acidic strength the ionisation of Schiff's base gets enhanced and it favours the adsorption strongly, thus increasing the inhibition efficiency.

Many investigators used Langmuir adsorption isotherm to study the characteristics of inhibitors $^{21-22}$. It has been supposed that inhibitors decrease the surface area of metals for electrochemical reaction to take place. Hoar and Holliday ${ }^{21}$ have shown that Langmuir isotherm 


$$
\log \left[\frac{\theta}{1-\theta}\right]=\log A+\log C-\frac{Q}{2.303 R T}
$$

should give a straight line of unit gradient for the plot between $\log \left[\frac{\theta}{1-\theta}\right]$ and $\log C$. $A$ is a constant which is independent of temperature and $\mathrm{C}$ is the bulk concentration of the inhibitor. The plots shown in Figure 2 are linear but the gradients are not equal to unity. The deviation may be due to the fact that adsorbed species interact with each other on the metallic surface.

\section{Conclusions}

A study of five synthesised bases viz. $N$-(furfurilidine) - 4- methoxy aniline ( $\left.\mathrm{SB}_{1}\right), N$-(furfurilidine) 4- methylaniline $\left(\mathrm{SB}_{2}\right), N$-(salicylidine) - 4- methoxy aniline $\left(\mathrm{SB}_{3}\right), N$-(cinnamalidine) - 4 -methoxy aniline $\left(\mathrm{SB}_{4}\right)$ and $N$-(cinnamalidine) - 2-methylaniline $\left(\mathrm{SB}_{5}\right)$ has shown them to be effective corrosion inhibitors for mild steel in $\mathrm{H}_{2} \mathrm{SO}_{4}$ acid. Mass loss and thermometric methods have indicated that the inhibition efficiencies increase with increasing strength of acid from $0.1 \mathrm{~N} \mathrm{H}_{2} \mathrm{SO}_{4}$ to $3 \mathrm{~N} \mathrm{H}_{2} \mathrm{SO}_{4}$ and with increasing concentration of inhibitors in the range from $5 \mathrm{ppm}$ to $40 \mathrm{ppm}$.

It has been observed that inhibiting effect has deviation from ideal Langmuir adsorption isotherm. This is due to the fact that molecules of adsorbed species interact with each other on the anodic and cathodic sites on the metallic surface.

\section{References}

1. Reverdtion F, Helv Chim. Acta, 1927, 10, 34.

2. Shabid P R and Adhe K N, J. Electrochem. Soc. 1981, 30, 103.

3. Quarisi M A, Rawat J and Ajmal M, Corrosion, its control, Proceedings,. Int. Conf. Corros., 1997, 2, 634.

4. Shabid P R, J. Electrochem. Soc. 1987, 27, 55.

5. Laskawiec J, Sozanska, Trzcionka B and Sukurczynska J, Koroz., 1995, 38, 249.

6. Shalaby M N, Osman M M and ElFeky A A, Anti corros. Meth. Mate., 1999, 46, 254.

7. Moretti G, Quartarone G, Tassar A and Zingales A, Electrochemica Acta, 1996, 41, 1971.

8. Achouri M, Kertit S, Salem M, Essassi E M and Jellal M, Bull. Electrochem, 1998, 14, 462.

9. Allah A G G, Tamous H M, Bull. Electrochem, 1995, 11, 178.

10. Rajendaran S, Apparo B V and Palaniswamy N, Anti Corros. Meth. Mate, 2000, 47, 294.

11. Bastidas J M, Damborenea J De and Lazquez A J, J.Appl. Electrochem., 1997, 27, 345.

12. Quraishi M A, Khan M A W, Jamal D and Ajmal M, Trans. Indian Inst. Metals, 1998, 51, 431.

13. Vishwanathan S and Rawat N S, Indian J.Technol., 1993, 31, 84.

14. Ajmal M, Rawat J and Quarishi M A, Anti corros. Meth. Mate., 1998, 45, 419.

15. Jaya Perumal D, Muralidharan S, Vankatachari G and Rangaswamy N S, Anti corros. Meth. Mate., 2000, 47, 349.

16. Ritu Chowdhary, Tripti Jain, Rathoria M K and Mathur S P, Bull. Electrochem., Paruthimal Kalaignan G, Gopalan A and Vasudevan T, Bull. Electrochem. 1999, $20,67$.

17. Sakthivel P, Nirmala P V, Umamaheshwari S, Alice Arul Antony A, Paruth, 83.

18. Talati J D and Gandhi D K, Ind. J. Tech. 1991, 29, 277.

19. Dubey R S and Uppadhyay S N, J.Electrochem. Soc., 1944, 43, 143.

20. Denny A Jones, Principles and Prevention of corrosion 1996, 2, 34.

21. Hoar T R and Holiday R D, J.Appl.Chem., 1953, 3, 582.

22. Mfakins J R, J.Appl.Chem., 1963, 13, 330. 


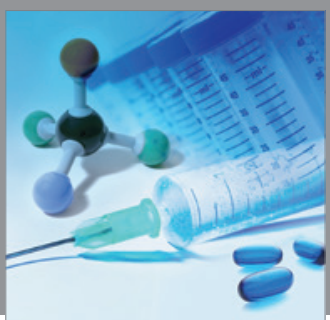

International Journal of

Medicinal Chemistry

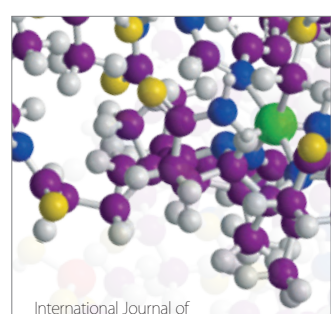

Carbohydrate Chemistry

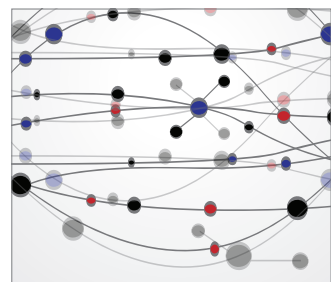

The Scientific World Journal
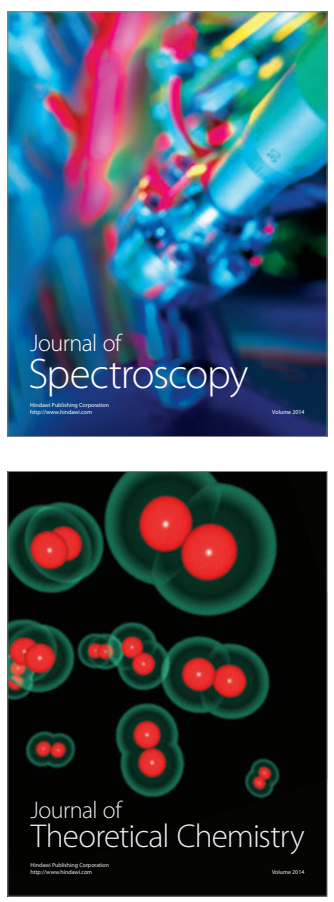
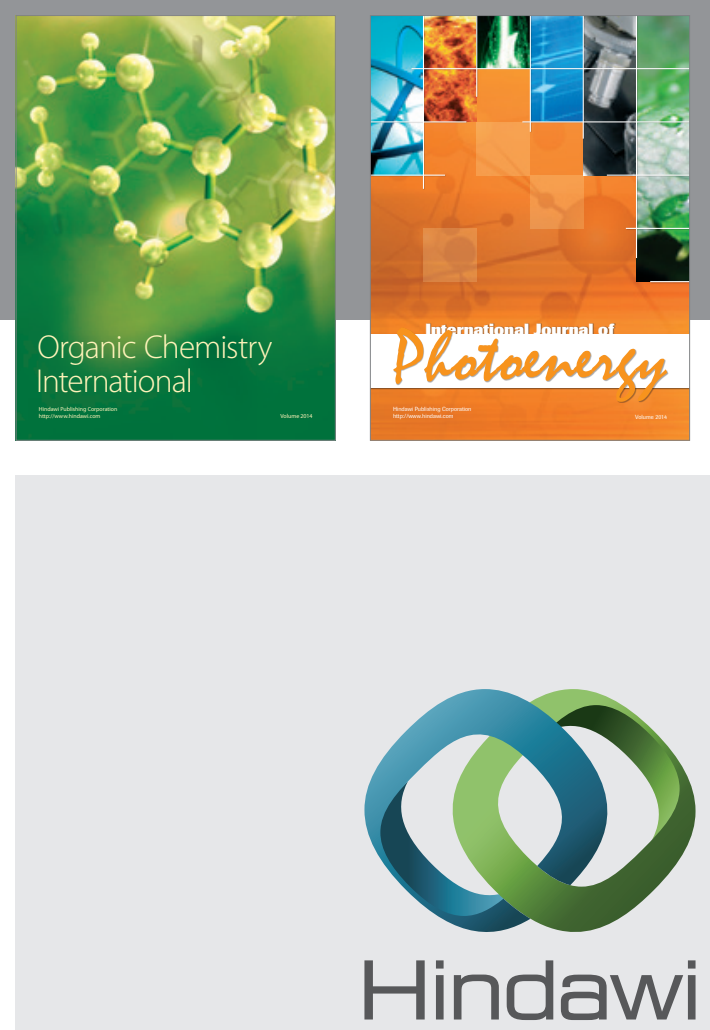

Submit your manuscripts at

http://www.hindawi.com
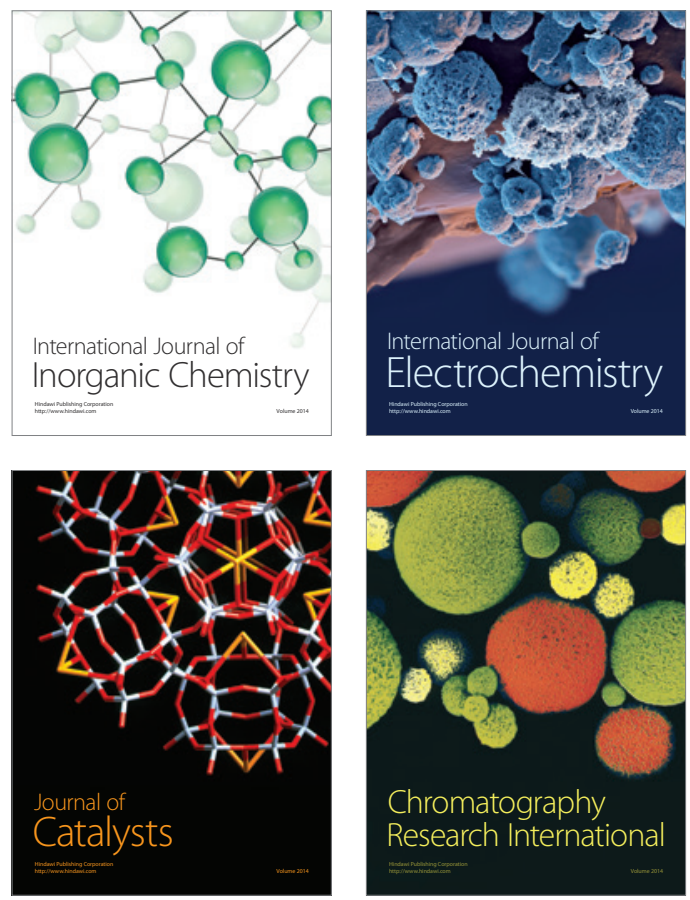
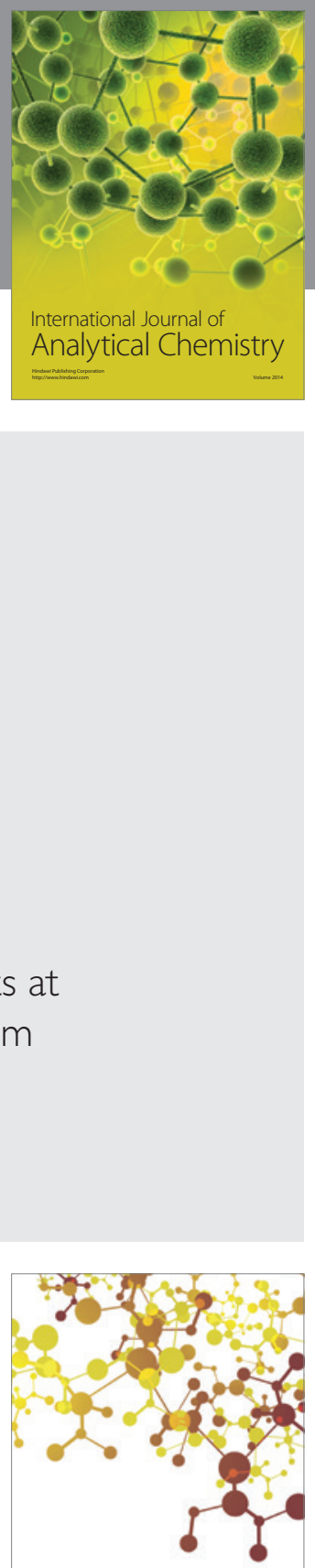

Journal of

Applied Chemistry
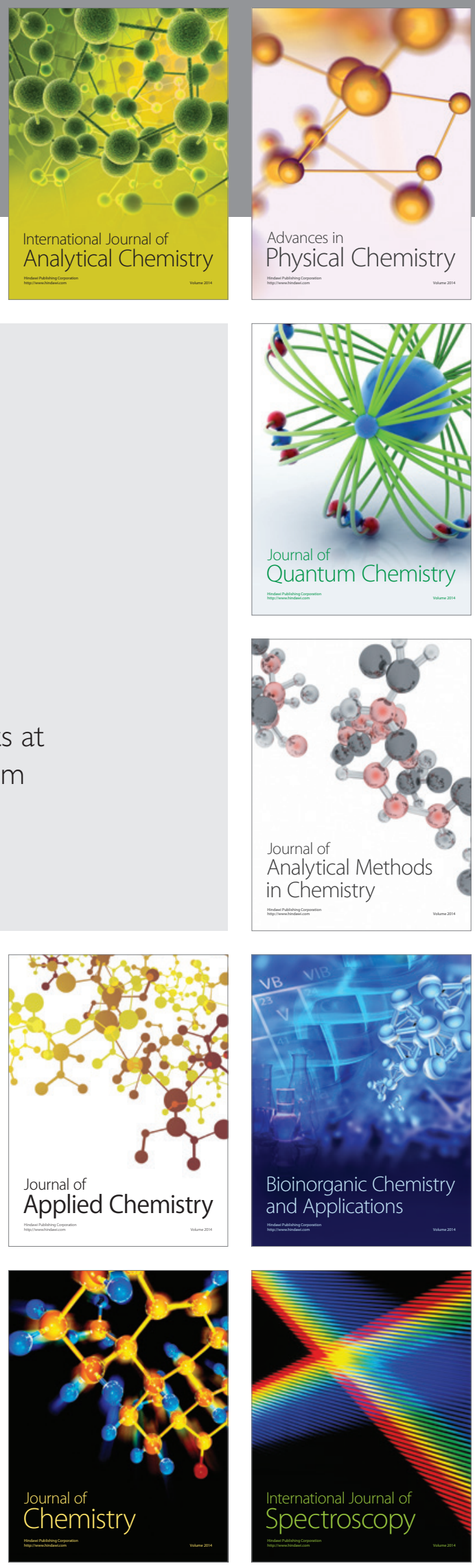